\section{$\underset{\substack{\text { hommes } \\ \text { \& migrations }}}{ }$}

\section{Hommes \& migrations}

Revue française de référence sur les dynamiques

migratoires

$1280 \mid 2009$

Les Turcs en France : quels ancrages?

\title{
Tassadit Imache, Des nouvelles de Kora
}

Paris, Actes Sud, 2009, 132 pages, 16 euros

\section{Mustapha Harzoune}

\section{(2) OpenEdition}

1 Journals

\section{Édition électronique}

URL : http://journals.openedition.org/hommesmigrations/336

DOI : 10.4000/hommesmigrations.336

ISSN : 2262-3353

\section{Éditeur}

Musée national de l'histoire de l'immigration

\section{Édition imprimée}

Date de publication : 1 juillet 2009

Pagination : 174-175

ISSN : 1142-852X

\section{Référence électronique}

Mustapha Harzoune, «Tassadit Imache, Des nouvelles de Kora », Hommes \& migrations [En ligne], 1280 | 2009, mis en ligne le 29 mai 2013, consulté le 22 septembre 2020. URL : http://

journals.openedition.org/hommesmigrations/336 ; DOI : https://doi.org/10.4000/hommesmigrations. 336

Ce document a été généré automatiquement le 22 septembre 2020.

Tous droits réservés 


\section{Tassadit Imache, Des nouvelles de Kora}

Paris, Actes Sud, 2009, 132 pages, 16 euros

Mustapha Harzoune

\section{RÉFÉRENCE}

Tassadit Imache - Des nouvelles de Kora, Paris, Actes Sud, 2009, 132 pages, 16 euros

1 Voilà un livre qui dérange, perturbe, ne laisse pas indifférent pour peu que l'on accepte de se coltiner un texte qui place le lecteur au cœur de la folie et des doutes qui brident une vie entière. Si la lecture Des nouvelles de Kora laisse perplexe, ce n'est pas à cause du style de Tassadit Imache, sobre et fluide. Ici, plus encore que dans ses précédents récits, l'auteur a pesé chaque mot, chaque phrase. D'ailleurs, rien n'est gratuit, tout a un sens et le stylo déploie le récit sur un mode quasi cinématographique, tant chaque phrase, le plus souvent courte, laisse échapper une image. Non, là où le lecteur se retrouve comme désemparé, c'est qu'il doit batailler avec une construction tout en labyrinthe, faite de retours en arrière, d'interrogations, de doutes, de fausses pistes... Tassadit Imache maîtrise parfaitement cette structure. Elle est peut-être le sel de ce récit : elle traduit le désordre mental et la confusion de l'existence. Elle dérange au point de laisser l'impression de passer à côté de l'essentiel. La vie elle-même, peut-être. Ce texte particulièrement pensé et travaillé conserve toute sa charge émotionnelle et pour peu qu'on accepte de le faire sien, c'est-à-dire d'y entrer en faisant l'effort de bousculer ses certitudes..., le trouble est alors garanti, et ce sans doute quelle que soit son histoire personnelle (on n'est pas obligé d'être la chanceuse rejeton d'un couple franco-algérien formé au temps de l'Algérie de papa comme le personnage de ce récit). Ce livre rend compte, traduit, fait ressentir, quasi physiquement, le malaise, le mal-être, le désordre intérieur, le désordre en soi, sui generis. Et le désordre de chacun peut alors trouver un écho dans l'histoire particulière de Michelle; et la gaine des certitudes s'effiloche devant le tableau des fragilités intimes. 
2 Michelle, la fille d'un couple franco-algérien, née en pleine guerre d'Algérie, a été placée à l'âge de cinq ans dans un centre pour enfants dirigé par "la Reine", une femme qui consignait sur des cahiers l'histoire de chacun de ses pensionnaires. Mais voilà ! "On avait le droit d'emporter son histoire! Mais vous m'avez laissée sortir seule dans ma vie. Je me suis perdue dehors [...]." Depuis cette lointaine et pourtant si actuelle enfance, Michelle soupçonne sa mère de lui avoir caché un secret.

3 Michelle, taciturne aux yeux pers, peu douée mais aussi sans concessions pour "la mécanique sociale", est écrivain. Kora, le personnage de son prochain roman, lui ressemble : elle est une "de ces bâtardes prêtes à vivre étouffées jusqu'à leur mort, les restes des leurs coincés dans la gorge pour survivre". Kora-Michelle ; Michelle-Kora; récit d'un dédoublement, d'un saut dans les mystères de l'enfance, d'une chute brutale et profonde qui expédiera Michelle dans un établissement psychiatrique où le Dr P. et elle noueront un mystérieux lien d'"enchantement".

4 Avec ce livre court, Tassadit Imache revient sur des thèmes déjà présents dans ses autres livres: mémoire, identité, exil, "bâtards" nés d'un couple franco-algérien, rapport à l'Autre et regard de l'Autre, avec pour toile de fond l'histoire de la France coloniale, de l'immigration, des banlieues, des relégations et autres représentations sociales et culturelles...

5 Selon la mère de Michelle, "vivre c'est fabriquer de l'oubli et du mensonge". De cette plongée dans l'inconnu de l'enfance et des origines, Michelle découvre la vanité et l'illusion de cette quête. Kazuo Ishiguro (Quand nous étions orphelins) et Ook Chung (Kimchi) offraient, sur des modes très différents, le même travail de mémoire et de filiation. Pour déboucher sur une illusion, l'anamnèse n'en est pas moins à l'origine d'une salutaire bifurcation : se rattacher à une généalogie et à une histoire ne doit pas signifier en porter le poids comme un fardeau. Reste la recherche d'une force, d'une énergie vitale et créatrice, dont les descendants cherchent à se saisir, tels des voleurs de feu :

"Encourager à la vie peut ne pas être une entreprise vaine, n'est-ce pas? Il faut que ma Kora parle enfin avec les gens ou elle coulera avec ses coups de dents, ses coups de griffes, au fond du fleuve?" 